11 | 2007

Varia

\title{
Autun (Saône-et-Loire), sondages dans l'enclos de la cathédrale Saint-Lazare
}

Sylvie Balcon-Berry et Walter Berry

\section{Q OpenEdition \\ 12 Journals}

Édition électronique

URL : https://journals.openedition.org/cem/1164

DOI : 10.4000/cem. 1164

ISSN : 1954-3093

Éditeur

Centre d'études médiévales Saint-Germain d'Auxerre

Édition imprimée

Date de publication : 15 août 2007

ISSN : 1623-5770

Référence électronique

Sylvie Balcon-Berry et Walter Berry, « Autun (Saône-et-Loire), sondages dans l'enclos de la cathédrale Saint-Lazare », Bulletin du centre d'études médiévales d'Auxerre | BUCEMA [En ligne], 11 | 2007, mis en

ligne le 30 août 2007, consulté le 22 septembre 2022. URL : http://journals.openedition.org/cem/1164 ; DOI : https://doi.org/10.4000/cem.1164

Ce document a été généré automatiquement le 22 septembre 2022.

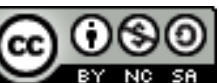

Creative Commons - Attribution - Pas d'Utilisation Commerciale - Partage dans les Mêmes Conditions 4.0 International - CC BY-NC-SA 4.0

https://creativecommons.org/licenses/by-nc-sa/4.0/ 


\title{
Autun (Saône-et-Loire), sondages dans l'enclos de la cathédrale Saint- Lazare
}

\author{
Sylvie Balcon-Berry et Walter Berry
}

1 Un rapide diagnostic archéologique mené en janvier 2006 par Yannick Labaune du Service municipal d'Archéologie en vue d'un aménagement paysager de l'enclos de la cathédrale Saint-Lazare par les Monuments historiques a révélé au sud-ouest l'existence d'un fossé de quatre mètres de large, orienté nord-sud. La mention d'une enceinte dans une charte de la fin du XIIe siècle nous a incités à demander l'autorisation de fouiller cette structure de façon plus approfondie.

2 Notre opération réalisée en août 2006 avec des étudiants de l'Université Paris IVSorbonne s'est limitée à deux tranchées parallèles situées à l'ouest du chœur de la cathédrale : une au sud qui consistait en la reprise du diagnostic de janvier 2006, et une au nord, vierge de toute intervention. Elle nous a conduits à mettre au jour une enceinte de terre et bois datant de l'époque mérovingienne, plusieurs fois remaniée jusqu'au XIIe siècle, qui avait pour but de protéger le groupe épiscopal.

3 Nous avons pu observer l'aménagement d'un premier fossé orienté nord-sud à ouverture très évasée, avec structure massive en bois à l'est (partie d'une palissade ou d'une porte, voire les deux), le tout remontant à l'époque mérovingienne. Ces éléments ont perturbé des niveaux antiques (Ier siècle) bien observés à l'ouest. Le fossé étant très évasé et la zone de fouille limitée, il n'a pas été possible de fouiller les vestiges d'occupations plus récentes creusées par cette fortification. Elle passait immédiatement à l'ouest d'un grand bâtiment orienté est-ouest, situé à l'ouest de l'ancienne cathédrale Saint-Nazaire, partiellement mis au jour en 1991 lors des fouilles du chœur de SaintLazare et à l'occasion des récents travaux de voirie réalisés au sein du groupe épiscopal (place du Terreau). Cet édifice à colonnes adossées et sol en mortier de tuileau pourrait remonter à l'époque mérovingienne et correspond peut-être à la matricula (espace d'accueil des pauvres) mentionnée dans les sources relatant l'épiscopat de saint Léger. La fortification ne devait pas être linéaire mais comporter des retours vers l'est, tant au 
nord qu'au sud. On peut imaginer qu'elle formait un grand rectangle protégeant le groupe épiscopal tel qu'il se présentait à l'époque mérovingienne.

4 Ce fossé a été remanié à l'époque carolingienne avec aménagement d'une pente à l'est associée à une levée de terre et pierre remplaçant la palissade (voire la porte) primitive. $\mathrm{Au}$ XIe siècle, une ample restructuration observée lors des fouilles effectuées dans le chœur de Saint-Lazare a notamment entrâné la disparition de la supposée matricula. En ce qui concerne l'enceinte, on a pu montrer la réfection de la levée de terre orientale qui devait porter en son sommet une palissade de bois, des trous de poteaux ayant été notés au nord. À l'ouest, la naissance de la levée de terre butait apparemment contre une structure de bois : pieux ou pile pour pont dormant ou passerelle, si l'on imagine la présence d'une porte plus à l'est, venue en remplacer une plus ancienne.

5 L'abandon de cette fortification date vraisemblablement de la fin du XIIe siècle. Notons que cette vaste structure défensive a peut-être dans une certaine mesure conditionné l'orientation anormale de Saint-Lazare qui lui est parallèle. Elle devait donc toujours être profondément ancrée dans le paysage urbain au moment de la construction de cette église, au début du XIIe siècle. La suppression de cette enceinte coïncide vraisemblablement avec la création, à la fin du XIIe siècle, d'une autre fortification, cette fois de pierre prenant en compte la nouvelle configuration du groupe épiscopal, Saint-Lazare compris, ainsi que le groupe canonial, dont il subsiste des vestiges notamment la Porte du Chapitre.

6 L'intervention de l'été 2006 a donc été particulièrement fructueuse puisqu'elle a permis de mettre en évidence la présence d'une vaste fortification de terre et bois cernant le groupe épiscopal à l'époque mérovingienne, plusieurs fois restructurée. Elle apporte une donnée essentielle à notre connaissance du développement du complexe cathédral. On serait tenté d'attribuer cette enceinte à saint Léger, grand évêque du VIIe siècle, qui s'est opposé au pouvoir laïc et dont l'action édilitaire est relatée dans les textes. Soulignons que la présence d'un autre fossé, plus à l'ouest, n'est pas à exclure, à l'instar de ce qui a été observé à Saint-Denis en ce qui concerne l'enceinte du bourg monastique carolingien. De plus, outre l'état de conservation particulièrement bon de la fortification que nous avons étudiée, précisons qu'il est très rare de pouvoir fouiller de telles structures en milieu urbain. 


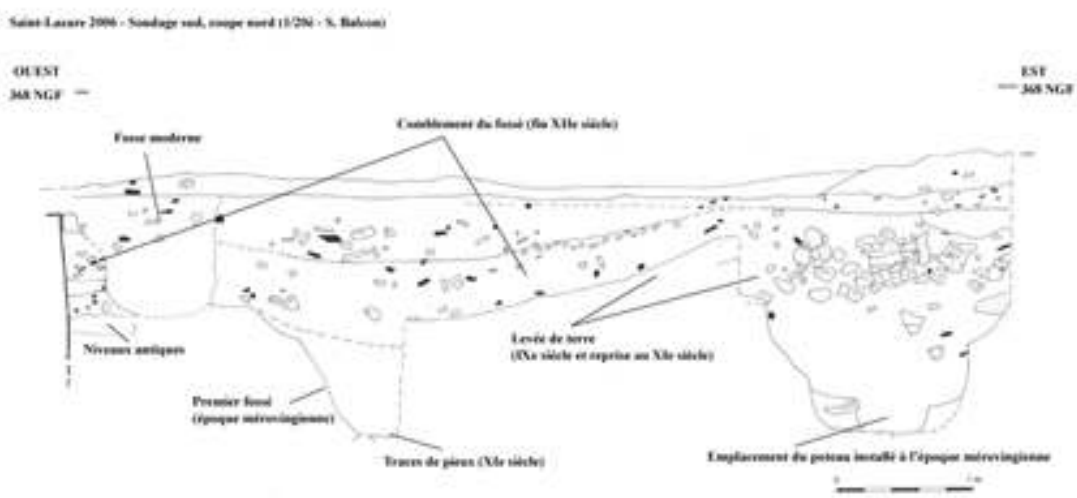

INDEX

Mots-clés : Lazare (saint), cathédrale, Saint-Lazare d'Autun, enclos Index géographique: France/Autun 